\title{
Structure-performance-fouling studies of polysulfone microfiltration hollow fibre membranes
}

\author{
P S SINGH*, K PARASHURAM, S MAURYA, P RAY and A V R REDDY \\ RO Membrane Division, Central Salt and Marine Chemicals Research Institute (Council of Scientific and Industrial \\ Research), Bhavnagar 364 002, India
}

MS received 13 October 2011; revised 6 January 2012

\begin{abstract}
Hollow fibre microfiltration membranes were prepared by solution spinning process using polymer dope containing different amounts of polysulfone (PS), polyvinylpyrollidone (PVP) and $N, N$-dimethylformamide (DMF). Spinning dope having PS: PVP: DMF (w/w) of 15: 5: 80, 15: 7: 78 and 17: 8: 75 were used for spinning to obtain hollow fibres having different dimensions (outer and inner diameters) and pore characteristics. Relatively high water permeability was observed for hollow fibre membrane spun from $15 \mathrm{wt}$ \% solution than $17 \mathrm{wt}$. \% PS solution having the same PVP/PS ratio of 0.47. Decrease of the PVP/PS ratio to 0.33 in the dope solution of 15 wt. \% PS solution produced hollow fibre membrane with lower flux. By changing the spinning parameters, fibre with different dimensions were obtained without a significant change in microstructural morphology. The flux decline due to fouling for the permeation of PEO/BSA solution was maximum for the hollow fibre membrane obtained from $15 \mathrm{wt}$ \% PS solution while a steady flux with slight fouling was observed for the hollow fibre membrane obtained from 17 wt. \% PS solution, when the PVP/PS ratio was 0.47.
\end{abstract}

Keywords. Microfiltration; structure; performance; fouling; transport properties.

\section{Introduction}

Microfiltration (MF) is a process for separating particles with diameters between $0 \cdot 1$ and 10 micrometer from suspensions by passing the liquid through a porous membrane and it is the oldest separation technique among the pressure-driven membrane separation processes known today (Baker 2004; van Reis and Zydney 2007; Tung et al 2010). Unfortunately, fouling of the microfiltration membranes is the main reason why microfiltration processes has limited applications in industrial uses (Mueller and Davis 1996; Nabe et al 1997; Czekaj et al 2000). Polymer additives such as polyvinylpyrrolidone (PVP) is widely used for the structure control of ultrafiltration and microfiltration membranes obtained by the phase inversion process (Lafreniere et al 1987; TorrestianaSanchez et al 1999; Ochoa et al 2001; Jung et al 2004). The addition of PVP to the polymer solution resulted in the formation of membrane with larger porosity. During the phase inversion process, it is assumed that the hydrophilic additive, PVP, is removed by dissolution in water and the sites where PVP existed became micropores (Wienk et al 1995). It is reported that the decrease in the concentration of PVP results in lower water flux and higher rejection (Wang et al 1999). A hydrophobic polymer is often blended with PVP to increase hydrophilicity for specific applications. In such case where the PVP remained at the surface of the pore walls, a low water permeability can occur because of narrowing

*Author for correspondence (puyam@csmcri.org) of the pore diameter due to swelling of PVP (Wienk et al 1995; Qin et al 2003). Removal of PVP from such membrane using hypochlorite treatment may enhance the water flux as hypochlorite leached the PVP by chain scission.

Fouling is a matter of great concern for all pressure-driven membrane processes. Systematic studies of protein microfiltration are very important for industrial applications. It is commonly accepted that aggregation and deposition of proteins on the membrane are responsible for membrane fouling (Kelly and Zyndney 1997). Aggregation of proteins is the main cause of fouling even though the pore size of membrane is much larger than the protein size (Tung et al 2010). Protein fouling of microfiltration membranes is influenced by many factors, such as properties of the membrane and those of the protein solution and operating parameters. The protein adsorption on MF membrane during filtration is poorly understood because of the difficulties in distinguishing the protein adsorption onto pore and membrane surface. Many researchers have indirectly distinguished the location of fouling in terms of flux decline with the blocking filtration models (Nakamura and Matsumoto 2006; Sun et al 2008). In this paper, the asymmetric microfiltration hollow fibre membranes are prepared using polymer dope containing different amounts of PS, PVP and DMF. The effect of PS/PVP concentration on morphological and transport properties of the membranes has been studied. The fouling of the membranes by PEO/BSA solution is discussed. The transport properties and fouling tendency of the membranes before and after hypochlorite treatment are also presented. 


\section{Experimental}

\subsection{Materials}

Polysulphone (UDEL 3500) from Solvay Advanced Polymers (USA), polyvinylpyrrolidone (MW 40000) from Aldrich (Germany), and DMF from Qualigen Fine Chemicals, India were used for the membrane preparation. Polyethylene oxide (MW 100,000) from Aldrich (Germany) and BSA (Albumin bovine Fraction V) from Spectrochem India were used for permeation studies.

\subsection{Preparation and characterization of hollow fibre MF membranes}

Three dope solutions having PS:PVP:DMF (w/w) of 15:5:80, $15: 7: 78$, and $17: 8: 75$, respectively were used for the spinning of the hollow fibre. The dope solution was extruded through a double orifice spinneret in nitrogen environment. The water flowed through the inner nozzle of the spinneret acting as bore former. The fibres of different dimensions were also prepared by changing the operational parameter of spinning such as polymer extrusion rate and winding rate. The details of experimental parameters used in spinning are summarized in table 1 . The fibres were rinsed in flowing water at room temperature for $72 \mathrm{~h}$. The membrane cartridges were made from the hollow fibres and evaluated for their transport properties at about 2 psi. The solute rejection was calculated using the following expression

Solute rejection, $R, \%=\left(1-C_{\mathrm{P}} / C_{\mathrm{F}}\right) \times 100$,

where $C_{\mathrm{F}}$ and $C_{\mathrm{P}}$ are concentrations of solute in the feed and permeate, respectively. Contact angle (water) on the surface of the fibres was measured according to sessile drop method using DSA 100E model. The FT-IR spectra were obtained with Perkin Elmer 16 PC FT-IR Spectrophotometer. Morphology of the membranes were observed using optical microscopy and atomic force microscopy NT-MDT model. Zeta potential of the membranes were measured by ZETA-CAD instrument using $10 \mathrm{mmol}$ aqueous solution of

Table 1. Performance studies of MF-hollow fibre membrane modules.

\begin{tabular}{|c|c|c|c|c|c|c|c|c|}
\hline \multicolumn{2}{|c|}{ Samples } & \multirow{2}{*}{$\begin{array}{l}\text { Spinning } \\
\text { dope }^{\mathrm{a}}\end{array}$} & \multirow{2}{*}{$\begin{array}{c}\text { Winding } \\
\text { rate }(\mathrm{m} / \mathrm{min})\end{array}$} & \multicolumn{2}{|c|}{ Diameter (mm) } & \multirow[b]{2}{*}{$\mathrm{PWP}^{\mathrm{b}}$} & \multicolumn{2}{|c|}{ Rejection (\%) } \\
\hline Type & Series & & & Inner & Outer & & PEO & BSA \\
\hline \multirow[t]{2}{*}{$A$} & 651 & $15: 7: 78$ & $21 \cdot 0$ & 0.94 & 1.60 & 1350 & $77 \cdot 5$ & $95 \cdot 6$ \\
\hline & 661 & $15: 7: 78$ & $27 \cdot 1$ & $1 \cdot 11$ & 1.73 & 1440 & $76 \cdot 3$ & $95 \cdot 5$ \\
\hline \multirow[t]{2}{*}{$B$} & 671 & $15: 5: 80$ & $28 \cdot 2$ & 0.95 & $1 \cdot 50$ & 1235 & $83 \cdot 2$ & $95 \cdot 3$ \\
\hline & 672 & $15: 5: 80$ & $23 \cdot 5$ & 0.95 & $1 \cdot 60$ & 1200 & $85 \cdot 0$ & $96 \cdot 5$ \\
\hline \multirow[t]{3}{*}{$C$} & 681 & $17: 8: 75$ & $31 \cdot 0$ & $0 \cdot 86$ & $1 \cdot 30$ & 769 & $78 \cdot 5$ & $93 \cdot 5$ \\
\hline & 682 & $17: 8: 75$ & $37 \cdot 9$ & $0 \cdot 81$ & $1 \cdot 30$ & 678 & $77 \cdot 9$ & $95 \cdot 2$ \\
\hline & 683 & $17: 8: 75$ & $35 \cdot 9$ & $0 \cdot 80$ & 1.45 & 564 & $81 \cdot 2$ & $96 \cdot 0$ \\
\hline
\end{tabular}

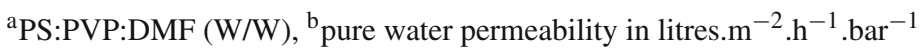

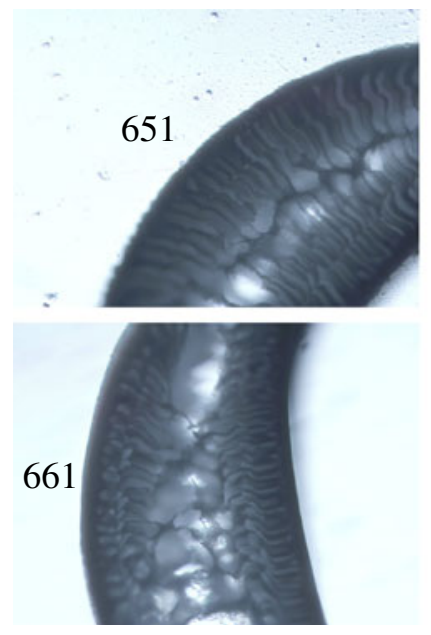

(Type A)

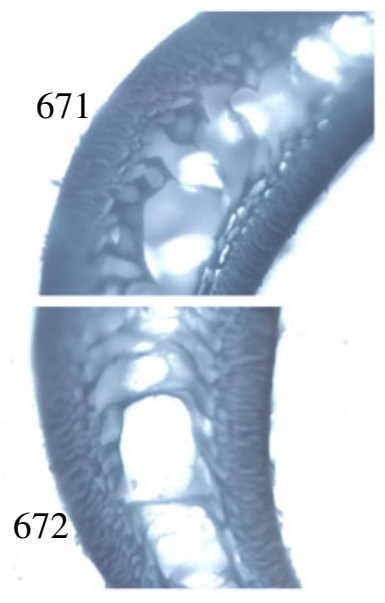

(Type B)

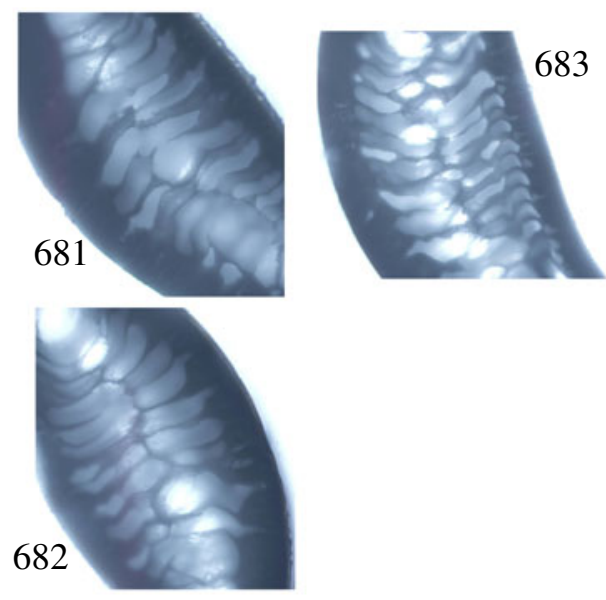

(Type C)

Figure 1. Optical microscope images of three types of hollow fibres. Type $A$ (samples 651, 661); type $B$ (samples 671, 672) and type $C$ (samples 681, 682, 683). 
$\mathrm{KCl}$. Fouling experiments on the fresh and $\mathrm{NaOCl}$ treated membranes were conducted using PEO (100 kDa) $500 \mathrm{mg} / \mathrm{l}$ and BSA (67 kDa) $500 \mathrm{mg} / \mathrm{l}$ aqueous solutions.

\section{Results}

\subsection{Pure water permeation and separation performance}

The flux and separation performances of the membranes are given in table 1 . Types $A, B$ and $C$ fibres were spun from the 15:7:78, 15:5:80 and 17:8:75 PS:PVP:DMF dope solutions, respectively. Fibres dimensions in terms of outer and inner diameter were found to be in the $1.30-1.73$ and 0.80 $1.11 \mathrm{~mm}$ ranges, respectively. In general, the fibres spun from 15 wt. \% PS solution were of larger diameter (about $20 \%$ increase in size) than the fibres obtained from $17 \mathrm{wt} . \%$ PS solution. The fibre dimension obtained was also dependent on the spinning operational parameters such as polymer extrusion rate and winding rate. The pure water permeability of the membrane (samples 651, 661) made from dope solution having PS:PVP:DMF (w/w) of 15:7:78, respectively was found as 1350 litres. $\mathrm{m}^{-2} \cdot \mathrm{h}^{-1} \cdot \mathrm{bar}^{-1}$, whereas the fluxes of the membranes (671 and 672) prepared from the dope solution having PS:PVP:DMF (w/w) of 15:5:80, respectively had relatively lower water permeability. This implies increase of

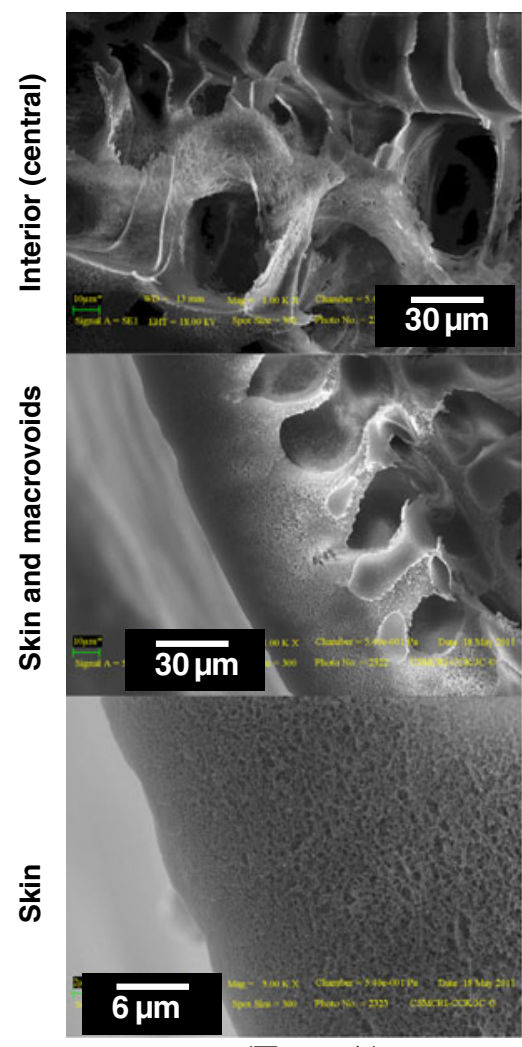

(Type A)

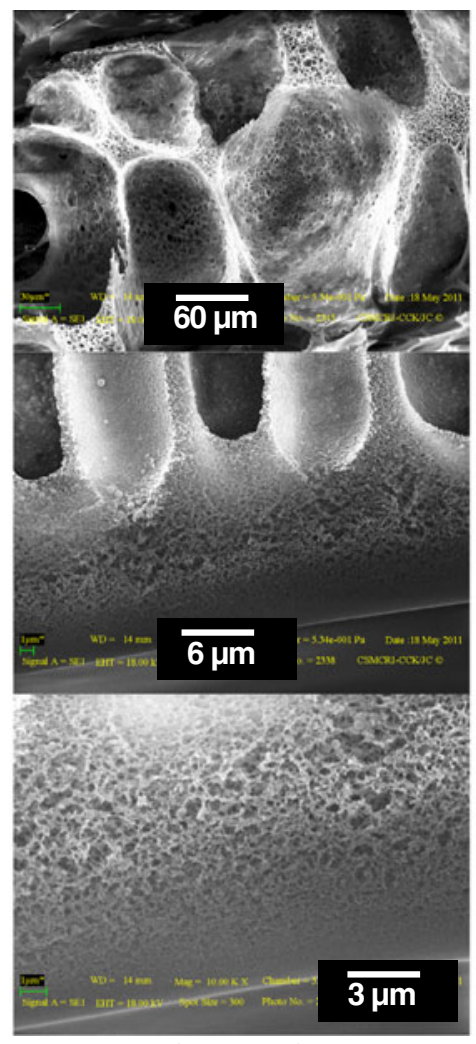

(Type B)

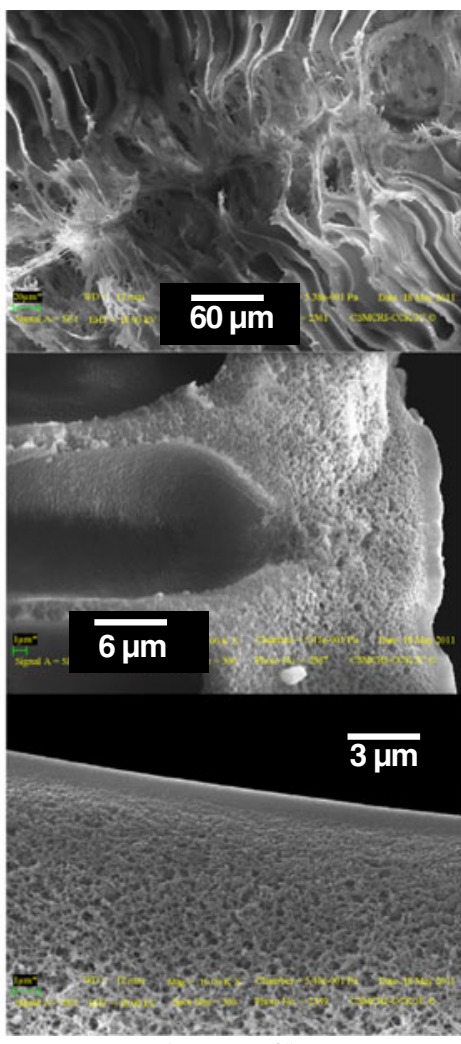

(Type C)

Figure 2. SEM images of hollow fibre of types $A, B$ and $C$.

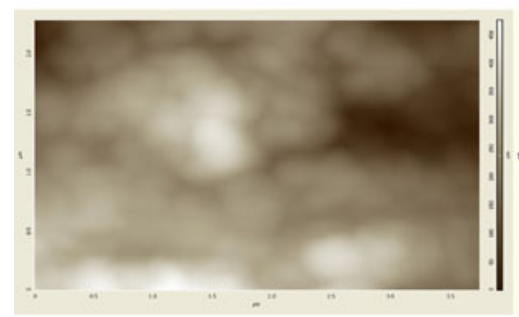

Type A

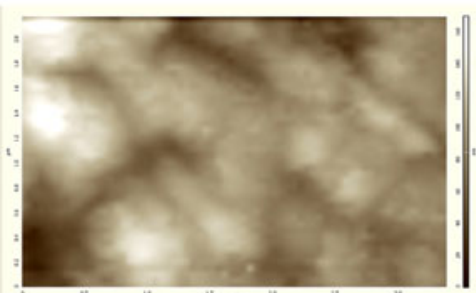

Type B

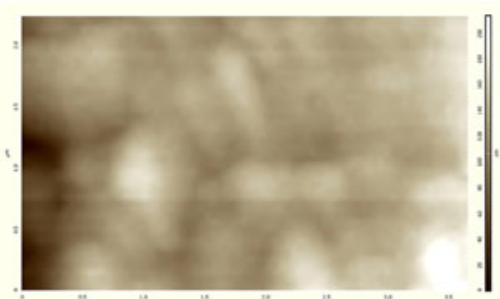

Type C

Figure 3. 2 dimensional AFM outer surface images of three types of hollow fibres; image frame size is $2.5 \mu \mathrm{m}$ $(X$-direction $) \times 3.5 \mu \mathrm{m}(Y$-direction $)$. 
water flux for the membranes with increase in PVP content. On the other hand, a relatively higher water flux was observed for the membranes made from $15 \mathrm{wt}$. \% solution $(651,661)$ than 17 wt. \% PS solution $(681,682,683)$ having the same PVP/PS ratio of $0 \cdot 47$. All the membranes, however, have similar performances in terms of selectivity as observed by similar rejection efficiency of PEO and BSA solutes.

Table 2. Roughness analysis of surface images of figure 3.

\begin{tabular}{lrrr}
\hline Sample & Type A & Type B & Type C \\
\hline Max. peak height (nm) & 475 & 169 & 213 \\
Mean value a (nm) $_{\text {Roughness average (nm) }}$ & 232 & 89 & 123 \\
\hline
\end{tabular}

${ }^{a}$ the first moment of distribution

Table 3. Contact angle (water) and surface wetting energy (water) for membranes.

\begin{tabular}{lll}
\hline Membrane & Contact angle $\left(^{\circ}\right)$ & Surface energy $\left(\mathrm{mJ} / \mathrm{m}^{2}\right)$ \\
\hline Type $A$ & $70 \cdot 4$ & $24 \cdot 32$ \\
Type $B$ & 73 & 23.53 \\
Type $C$ & $76 \cdot 5$ & 22.46 \\
\hline
\end{tabular}

Figures 1 and 2 show optical microscope and SEM cross-sectional images of the fibres. All the fibres clearly show asymmetric structure comprising of dense skin and macrovoids underneath. Each type has distinctive microstructure morphology. Type $A$ fibres have thinnest skin while type $B$ samples have large macrovoids in the centre and type $C$ fibres have denser skin with homogenously distributed macrovoids. The surface morphology of these three types of the membranes were characterized using atomic force microscopy. Figure 3 shows AFM surface images of the samples. The roughness analysis was performed on the images taken. As shown in table 2, among the 3 types of hollow fibre membranes, maximum surface roughness (maximum peak height of $475 \mathrm{~nm}$ with roughness average of $78 \mathrm{~nm}$ ) was observed for type $A$ sample which agrees well with a lowest contact angle (water) of $70.4^{\circ}$ which is $\sim 4-8^{\circ}$ lower than those of types $B$ and $C$ samples (table 3 ). Among the three membranes, type $A$ exhibited highest surface wetting energy (water).

\subsection{Fouling studies}

The three membrane types (types $A, B, C$ ) were treated with $\mathrm{NaOCl}$ to leach out PVP from the surface of the fibres. The fouling trend on the fresh and treated membranes were then observed using the permeation runs of aqueous PEO and BSA solutions. Results are shown in figure 4 (i). Here relative
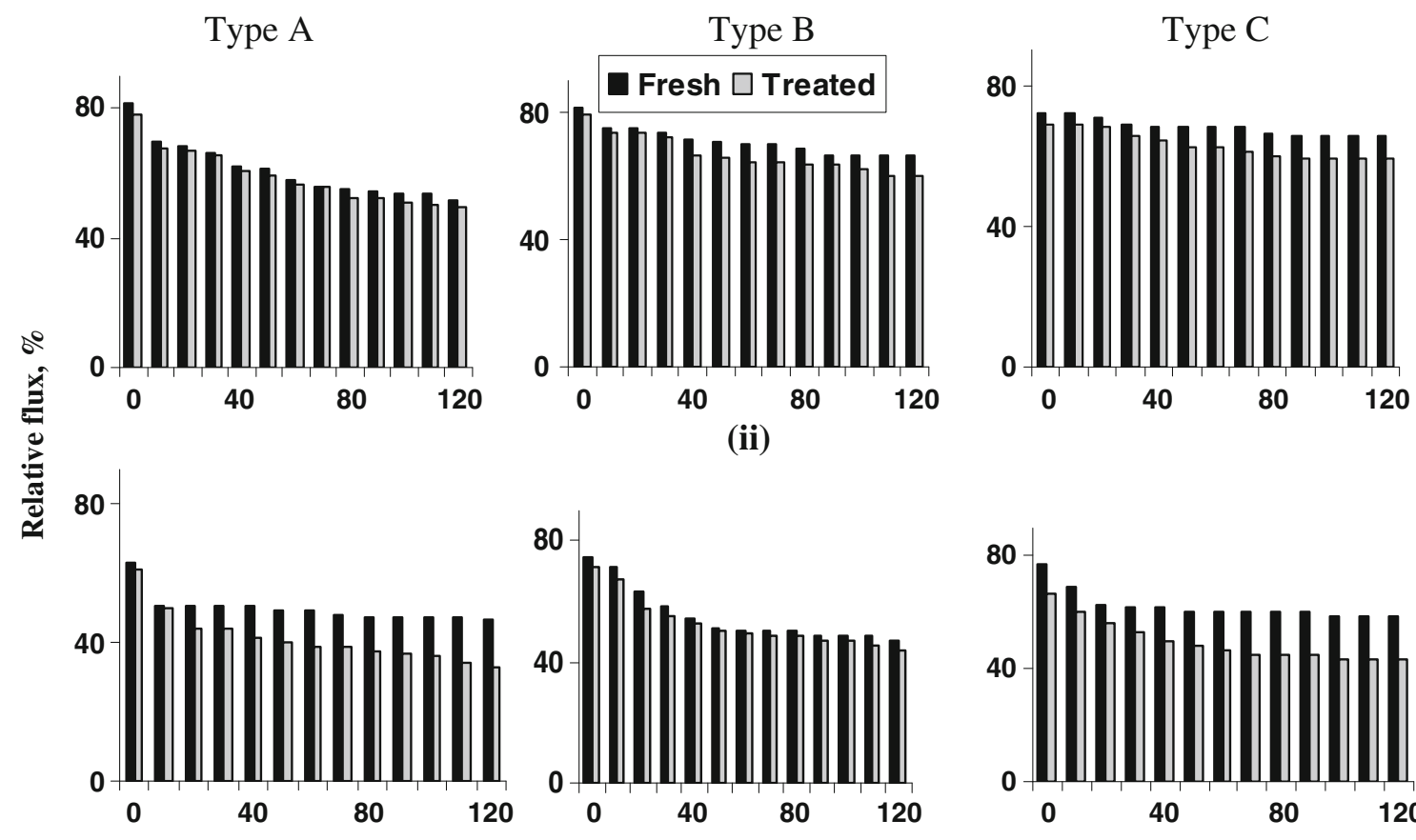

(ii)
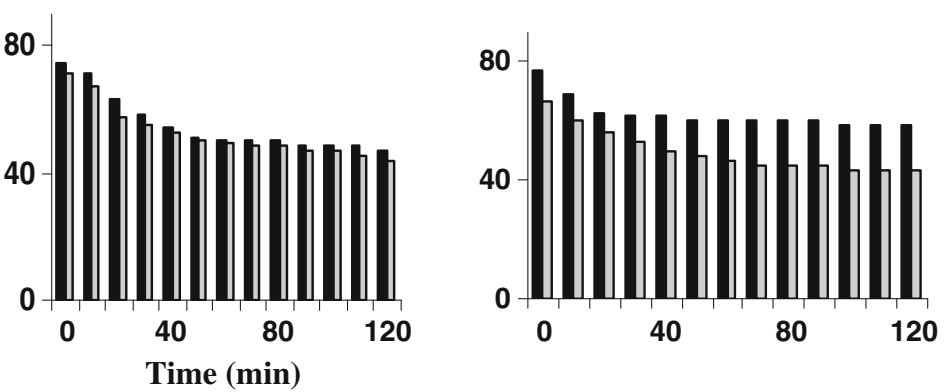

(i)

Figure 4. (i) Plot of relative flux vs time for types $A, B$ and $C$ membranes from permeation experiments using a $500 \mathrm{mg} / \mathrm{L}$ aqueous solution of PEO and (ii) plot of relative flux vs time for types $A, B$ and $C$ membranes from permeation experiments using a $500 \mathrm{mg} / \mathrm{L}$ aqueous solution of BSA. 
Table 4. FRR values and initial fluxes for fresh and treated membranes.

\begin{tabular}{|c|c|c|c|c|c|c|c|c|}
\hline \multirow{3}{*}{$\begin{array}{l}\text { Sample } \\
\text { Type } A\end{array}$} & \multicolumn{4}{|c|}{ Flux (litres.m $\left.\mathrm{m}^{-2} \cdot \mathrm{h}^{-1} \cdot \mathrm{bar}^{-1}\right)$} & \multicolumn{4}{|c|}{ FRR\% } \\
\hline & \multicolumn{2}{|c|}{ PEO } & \multicolumn{2}{|c|}{ BSA } & \multicolumn{2}{|c|}{ PEO } & \multicolumn{2}{|c|}{ BSA } \\
\hline & 683 & 768 & 675 & 749 & $82 \cdot 2$ & $74 \cdot 5$ & $82 \cdot 2$ & $74 \cdot 5$ \\
\hline Type $B$ & 880 & 920 & 830 & 853 & $80 \cdot 0$ & $78 \cdot 3$ & $80 \cdot 0$ & $78 \cdot 0$ \\
\hline Type $C$ & 532 & 638 & 512 & 595 & $92 \cdot 3$ & 88.8 & 92.0 & 88.0 \\
\hline
\end{tabular}
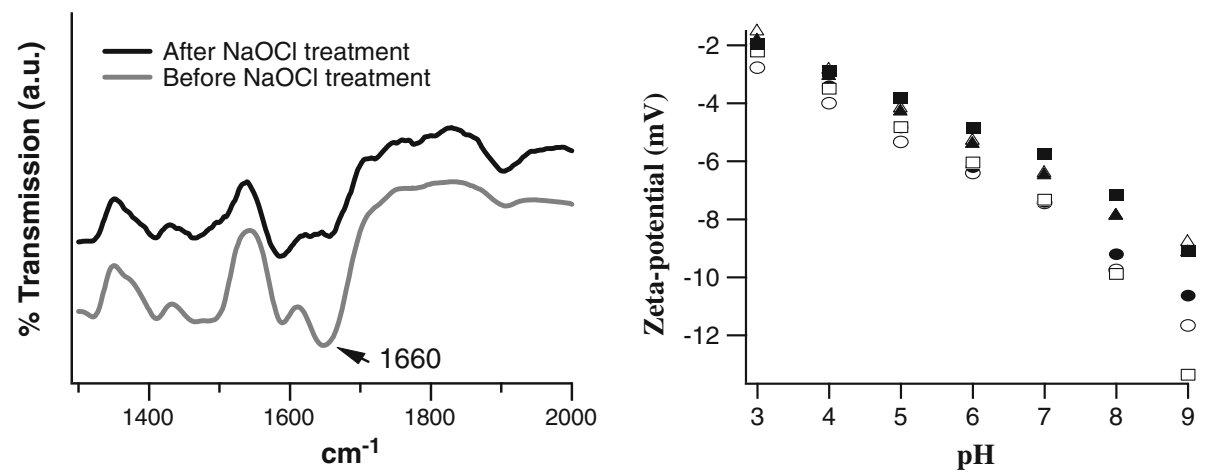

Figure 5. (i) FT-IR spectra of membrne samples before and after $\mathrm{NaOCl}$ treatment and (ii) zeta-potential values of membrane samples before and after $\mathrm{NaOCl}$ treatment. Filled markers indicate fresh samples and empty markers indicate treated samples. Type $A(\circ, \bullet)$; type $B(\square, \mathbf{\square})$; type $C(\Delta, \mathbf{\Delta})$.

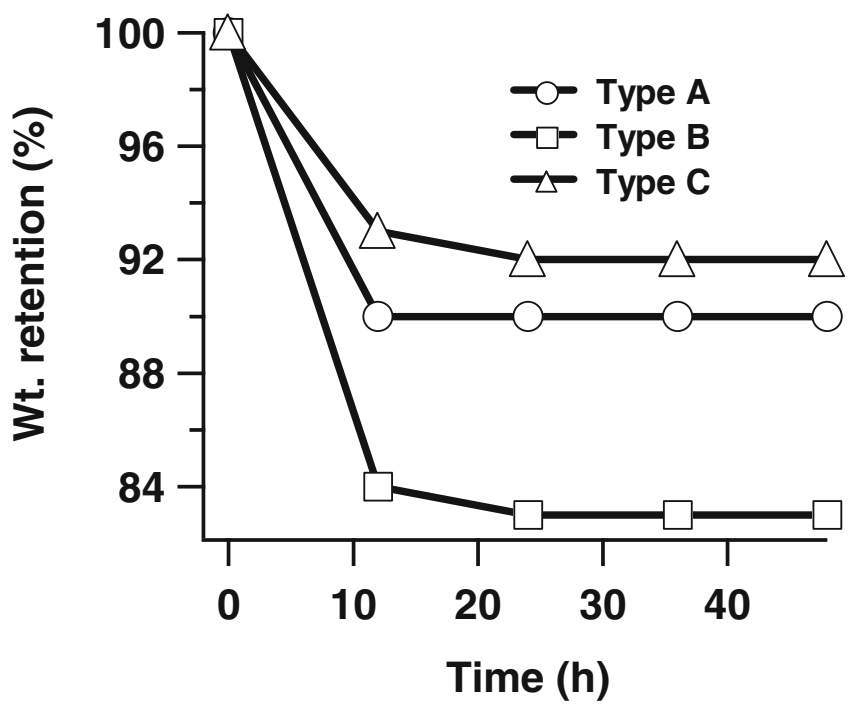

Figure 6. Loss of membrane weight with leaching time.

flux $(\mathrm{RF})$ is defined as the ratio of steady flux at the end of the run period to the original pure water flux. As seen in the figure, after $2 \mathrm{~h}$ filtration of PEO, the flux of fresh types $A, B$ and $C$ membranes was about $53.6 \%, 53.3 \%$ and $41.5 \%$, respectively. Whereas the relative fluxes were $66.85 \%, 56.02 \%$ and $56.5 \%$ for treated hollow fibre of types $A, B$ and $C$ membranes, respectively. In the case of filtration of BSA as shown in figure 4 (ii), the flux of fresh membranes and treated have about $33-48 \%$ and $40-51 \%$, respectively. Further, the flux recovery ratio (FRR) value, which is considered to measure fouling resistance nature of membrane, was calculated after the second run of pure water. For this purpose, a backwash was performed on the hollow fibre modules to remove layer of precipitated PEO and BSA if any on the surface of the membrane before resuming to the normal operation mode. Table 4 gives FRR values along with their initial fluxes. In the case of PEO filtration, the FRR values were $82.24 \%$, $80 \%$ and $92 \%$ for fresh types $A, B$ and $C$, respectively. The FRR values were found to be decreased by about $10 \%$ for the treated samples. This means that the treated samples are relatively more fouling prone.

The low fouling tendency may be because of the relatively more hydrophilicity of the untreated membrane due to the presence of hydrophilic PVP in the membrane structure. The removal of PVP upon $\mathrm{NaOCl}$ treatment was clearly seen as a decrease in $1660 \mathrm{~cm}^{-1}$ peak which is a characteristic PVP peak in the FT-IR spectra (figure 5 (i)). Slight increases in negative zeta potential values for the treated samples in comparison to those of fresh samples were observed (figure 5 (ii)). The loss of PVP by leaching with $\mathrm{NaOCl}$ as a function of time is shown in figure 6 .

\section{Conclusions}

Different types of hollow fibres were spun using 15-17 wt. \% polysulfone solution in DMF in presence of different 
amounts of polyvinylpyrollidone using a phase inversion process in which water was used as gelating 'non-solvent' medium. The fibres obtained from the dope solution of low polymer concentration with more amount of PVP have higher porosity and higher flux. The PVP remaining in the membrane structure led to increase in the membrane hydrophilicity and consequently increase in the flux. On removal of the PVP by $\mathrm{NaOCl}$ treatment, a further enhancement in the flux was observed, however, such membrane became more fouling prone.

\section{Acknowledgements}

We thank the Council of Scientific and Industrial Research (CSIR), New Delhi, for funding this work under a CSIR Network Project NWP-47.

\section{References}

Baker R W 2004 Membrane technology and applications (Chichester: John Wiley \& Sons Ltd.) 2nd ed.

Czekaj P, López F and Güell C 2000 J. Membr. Sci. 166199
Jung B, Yoon J K, Kim B and Rhee H-W 2004 J. Membr. Sci. 24345

Kelly S T and Zyndney A L 1997 Biotechnol. Bioeng. 5591

Kelly S T, Zyndney A L and Ho C-C 1999 J. Membr. Sci. 155261

Lafreniere L Y, Talbot F D F, Matsuura T and Sourirajan S 1987 Ind. Eng. Chem. Res. 262385

Mueller J and Davis R H 1996 J. Membr. Sci. 11647

Nakamura K N and Matsumoto K 2006 J. Membr. Sci. 280363

Nabe A, Staude E and Belfort G 1997 J. Membr. Sci. 13357

Ochoa N A, Pradanos P, Palacio L, Pagliero C, Marchese J and Hernandez A 2001 J. Membr. Sci. 187227

Sun X, Kanani D M and Ghosh R 2008 J. Membr. Sci. 320372

Susanto H, Stahra N and Ulbricht M 2009 J. Membr. Sci. 342153

Torrestiana-Sanchez B, Ortiz-Basurto R I and Fuente E B 1999 J. Membr. Sci. 15219

Tung K L, Li Y-L, Wang S, Nanda D, Hu C-C, Li C-L, Lai J-Y and Huang J 2010 J. Membr. Sci. 352143

Qin J-J, Wong F-S, Li Y and Liu Y-T 2003 J. Membr. Sci. 211139 Wang D, Li K and Teo W K 1999 J. Membr. Sci. 163211

van Reis R and Zydney A 2007 J. Membr. Sci. 29716

Wienk I M, Meuleman E E B, Borneman Z, Boomgaard A V and Smolders C A 1995 J. Polym. Sci: Part A: Polym. Chem. 3349

Wienk I M, Boom R M, Beerlage M A M, Bulte A M W, Smolders C A and Strathmann H 1996 J. Membr. Sci. 113361 